\title{
FOREW ORD
}

The Milbank Memorial Fund is an endowed operating foundation that works to improve health by helping decision makers in the public and private sectors acquire and use the best available evidence to inform policy for health care and population health. The Fund has engaged in nonpartisan analysis, study, research, and communication since its inception in 1905 .

Searching Eyes: Privacy, the State, and Disease Surveillance in America is the eighteenth of the California/Milbank Books on Health and the Public. The publishing partnership between the Fund and the University of California Press seeks to encourage the synthesis and communication of findings from research that could contribute to more effective health policy.

The authors of Searching Eyes offer a new approach to surveillance policy. They analyze surveillance as an issue in the politics of policy making for public health, which it has been for more than a century.

Fairchild, Bayer, and Colgrove, with a significant contribution from Daniel Wolfe, describe the practical tension between privacy and the welfare of society since the nineteenth century. Their extensive research in primary sources reveals how difficult it has been to make and implement surveillance policy. The book begins in the late nineteenth century when, as a result of advances in scientific knowledge, "public health officials moved," the authors write, "to pull chronic infectious disease into the ambit of public health surveillance." Next the authors describe significant occasions during the twentieth century when "many people with illness [for example, occupational disease, cancer, and birth defects] would demand the right to be counted so that the extent of their afflictions could serve as a prod for ... ameliorative legislation." This aspect of the history of surveillance, the authors find, "democratized" privacy as "different constituencies balanced privacy against what they perceived to be their own greater interests." 
The era of "democratic privacy" is likely to continue indefinitely as new issues of surveillance policy arise. One such issue is the tension between policy to create immunization registries and the privacy of parents and children. Another is likely to be whether and how to use information about routine laboratory testing of the blood of persons with diabetes to improve the quality of care for individual patients.

Daniel M. Fox President

Samuel L. Milbank

Chairman 